\title{
Prevalence and Associated Factors of Incidentally Diagnosed Prostatic Carcinoma among Patients Who Had Transurethral Prostatectomy in Tanzania: A Retrospective Study
}

\author{
Daniel Gunda ${ }^{{ }^{*}}$, Ibrahim Kido ${ }^{1}$, Semvua Kilonzo ${ }^{1}$, Igembe Nkandala ${ }^{1}$, John \\ Igenge $^{2}$, Bonaventura Mpondo ${ }^{3}$
}

\footnotetext{
OPEN ACCESS

Citation: Daniel Gunda, Ibrahim Kido, Semvua Kilonzo, Igembe Nkandala, John Igenge, Bonaventura Mpondo Prevalence and Associated Factors of Incidentally Diagnosed Prostatic Carcinoma among Patients Who Had Transurethral Prostatectomy in Northwestern Tanzania: A Retrospective Study. Ethiop J Health Sci.2017;28(1):11.

doi:http://dx.doi.org/10.4314/ejhs.v28i1. 3

Received: June 12, 2017

Accepted: June 14, 2017

Published: January 1, 2018

Copyright: (C) 2018 Daniel G. et al . This is an open access article distributed under the terms of the Creative Commons Attribution License, which permits unrestricted use, distribution, and reproduction in any medium, provided the original author and source are credited.

Funding: Nil

Competing Interests: The authors declare that this manuscript was approved by all authors in its form and that no competing interest exists. Affiliation and Correspondence:

${ }^{1}$ Department of medicine, Weill Bugando School of Medicine, 1464, Mwanza Tanzania

${ }^{2}$ Department of urology, Bugando medical center, 1370, Mwanza Tanzania

${ }^{3}$ Department of medicine, College of Health sciences, University of Dodoma, 395, Dodoma

*Email: daniel_rev2002@yahoo.com
}

\author{
ABSTRACT
}

BACKGROUND: Prostatic carcinoma carries a high morbidity and mortality if it is not diagnosed early. In resource limited countries, patients are at increased risk of being diagnosed late as they are operated for presumed benign prostatic hyperplasia. The information on the magnitude and risk factors of this problem in our setting could assist in the overall optimization of care of patients at risk.

METHODS: $A$ retrospective study of patients who underwent prostatectomy for presumed benign prostatic enlargement was done at Bugando University Hspital in Tanzania. Patients' age, creatinine levels, urological Ultrasound, prostate specific antigen and Biopsy results were analyzed using STATA 11. The prevalence of incidental prostatic cancer was calculated and logistic regression was done for factors associated with incidental prostatic cancer.

RESULTS: In total, 152 patients were included in this study. The median age was 69 (SD 9.4) years, 16 (10.53\%,) and 49 (32.24\%) participants had Hydronephrosis and elevated creatinine levels respectively. Eighty six (58.56\%) patients had $P S A>10 \mathrm{ng} / \mathrm{mL}$ and in total; 33 (21.71\%) had incidental prostatic carcinoma. The incidental prostatic carcinoma was independently associated with age of 70-80years $(A O R=2.8, p=0.013)$ and $P S A$ levels $>10 n g / m L$ $(A O R=3.2, p=0.014)$.

CONCLUSIONS: The prevalence of incidental prostatic carcinoma is high among patients undergoing transurethral prostatectomy for presumed benign prostatic hyperplasia in Tanzania with increased risk at age of 70-80 years and among those with PSA $>10 \mathrm{ng} / \mathrm{mL}$. A national awareness campaign coupled with focused screening of patients above 60 years could increase the detection rate of prostatic carcinoma and reduce the magnitude of incidental diagnosis of this disease.

KEYWORDS: Incidental prostatic carcinoma, PSA, Tertiary level hospital, Tanzania 


\section{INTRODUCTION}

Prostatic carcinoma is a common cause of morbidity and mortality among ageing population of male patients; with its prevalence and incidence varying globally depending on diagnostic advances (1). With advanced diagnostics in the developed world, prostatic carcinoma is reported to be one of the three most common carcinomas in men and one of the leading causes of cancer related deaths (2). Although the rates of prostatic carcinoma in developing countries are on increment, most cases are likely to be missed in resource limited countries due to the current diagnostic limitation (3) making the magnitude of the problem nonrepresentative and much lower as compared to developed countries.

In an autopsy study conducted by Alexandre and associates among men who died of causes other than prostate carcinoma, more than $35 \%$ of the samples had prostate cancer and most patients (25-51\%) had advanced lesions of Gleason score 7 or above. In this study, more than $60 \%$ of those who were older than 80 years had prostatic cancer (4). Stamatiou et al., having assessed the prevalence of prostatic carcinoma in autopsy tissues, reported an age independent prevalence of $18.8 \%$; with highest rate of $56.8 \%$ in the oldest age group (5). Another study by Haas and colleagues, involving 164 autopsy prostates, indicated that $47(29.0 \%)$ samples had prostate carcinoma and $20(12.2 \%)$ of them were clinically significant by histological criteria (6). These studies suggest that most patients with prostatic carcinoma go unnoticed and thus making a timely diagnosis of this malignancy an ongoing important clinical challenge, which is even more so in resource limited settings.

The available prevalence rates of prostatic carcinoma in live subjects from earlier studies are reported from examination of surgically obtained tissues, at times among patients who had not been suspected at all of having the malignancy before surgery. For example, earlier in 1992 Bostwick and colleagues, having assessed association between benign prostatic enlargement $(\mathrm{BPH})$ and prostatic carcinoma, found that up to $25 \%$ of the patients who underwent Trans Urethral Resection Prostatectomy (TURP) for presumed BPH had prostatic carcinoma (7). Furthermore, among patients who underwent surgery for presumed bladder cancer, $25-40 \%$ of them were found to have associated prostatic carcinoma $(8,9)$.

While clinical presentations are highly nonspecific for earlier stages of prostatic carcinoma, digital rectal examination (DRE) (10) and the available sonographic modalities are less sensitive to pick these manageable lesions. DRE with prostate specific antigen (PSA) coupled could increase the rate of detection and subsequently subject patients to biopsy for confirmation (11). DRE findings of either presence of a nodule, prostatic asymmetry, change in prostatic texture, bogginess of the prostate or seminal vesicles and adjacent organs have been shown to be highly suggestive of malignant growth (12). Biopsy and histologic examination in this subset of patients would therefore confirm the diagnosis and determine the Gleason score based on the extent to which the epithelium assumes a normal glandular structure (13). Even with this body of information, the literature on the magnitude of this problem is still scarce in our setting. This study therefore was designed to determine the prevalence and associated factors of incidentally diagnosed prostatic carcinoma among patients who underwent TURP at a tertiary level hospital in Northwestern Tanzania.

\section{MATERIALS AND METHODS}

Study design and setting: This was a retrospective hospital based cohort study which was conducted at Bugando Medical Center (BMC) in Mwanza Tanzania. BMC is a consultant and teaching hospital for the Lake and Western zones of the United Republic of Tanzania. It is situated along the shores of Lake Victoria in Mwanza City. The hospital has a capacity of 1000 beds with approximately 1000 employees. It is a referral center for tertiary specialists care for six regions, including Mwanza, Mara, Kagera, Shinyanga, Tabora, Kigoma and Simiyu. It serves

DOI: http://dx.doi.org/10.4314/ejhs.v28i1.3 
a catchment population of approximately 16 million people. Urology is a super specialized department which works in collaboration with internal medicine specialties at Bugando university hospital. Patients attended are usually referred in from the second level hospitals. Routinely patients with obstructive prostatic enlargement undergo urological ultrasound (UTS), renal function testing, screening for infection with Full Blood count and urinalysis. PSA is only done for selected cases which are suspicious of malignant prostatic enlargement. Most patients with presumed BPH undergo TURP as a preferred modality to open prostatectomy as it has shorter hospital stay. Prostate tissues are subsequently submitted for histological evaluation, and patients found to have prostatic carcinoma undergo surgical hormonal manipulation. Some patients are also put on medical hormonal manipulation when affordable, and radical prostatectomy is not readily done.

Study population: All patients who underwent TURP in 2015 for presumed BPH were included in this study. Tissues obtained from patients undergoing prostatectomy are usually submitted for histological examination on routine bases. Patients who underwent TURP for known prostatic carcinoma and those whose histological details were missing were excluded.

Sample size, enrolment and data collection: A minimum sample size of 100 patients was estimated from Kish Lisle formula (1965) for cross sectional studies, assuming an incidental carcinoma prevalence of $15 \%$ according to previous studies $(7,14)$, with a tolerable error of 0.05 at $95 \%$ confidence interval (CI). A urological registry was used to identify all patients who underwent TURP during the study period and their identifiers were used to trace their files and histological results. From the files, data of research interest including age, renal function test, PSA results, Urological UTS results, amount of prostatic tissue ressected and histological results were retrieved and recorded in a special tool. The details on histology results including the percentage of biopsy with malignancy cells, Gleason score depending on the extent to which the epithelium assumed a normal glandular structure and Gleason sum were noted.

Data management: The data were double entered and cleaned using Epi data version 3.1, and STATA version 11 (Stata Corp LP, college station, TX) was used for analysis. In this study, histological result with prostatic carcinoma in $<5 \%$ of the biopsy was recorded as $\mathrm{T} 1$ a while those with $>5 \%$ were recorded as $\mathrm{T} 1 \mathrm{~b}$ (15). The Gleason score of 2-4 was coded as low grade (well differentiated), while score of 5-7 and 810 were coded as moderate (moderately differentiated) and high grade (poorly differentiated) respectively as used in other study (13). The PSA results were categorized into two with $7 \mathrm{ng} / \mathrm{mL}$ as a cutoff point as used previously (16). Continuous variables were summarized as means with standard deviations (SD) and categorical variables were expressed as proportions with percentages. The proportion of patients with incidentally diagnosed prostatic carcinoma was calculated and univariate followed by multivariate logistic regression model was performed to determine the odds ratios and 95\% CI for factors associated with incidental prostatic carcinoma. All factors with $\mathrm{p}<0.2$ in the univariate analysis were included in the multivariate model. Factors were said to have a significant statistical association if the $\mathrm{p}$ value was less than 0.05 in the final model.

Ethical consideration: The permission to conduct this study and publish its results was obtained from the joint research and Ethical Board of the Catholic University of Health and Allied Sciences (CUHAS) and Bugando Medical Center (BMC). The patients' files were handled by researchers alone and patients' identifiers were not included in the analysis to further maintain confidentiality.

\section{RESULTS}

Demographic and clinical characteristics of 152 study participants : In the year 2015, a total of 152 patients underwent TURP for presumed $\mathrm{BPH}$ and all were included in this study. The mean age of study participants was 69 (SD 9.4)

DOI: http://dx.doi.org/10.4314/ejhs.v28i1.3 
years and about two thirds; 101 (66.44\%) of them were between the age of 60 to 80 years. All patients were operated following obstructive prostatic symptoms, where $16(10.53 \%)$ were found to have Hydronephrosis, and 49 (32.24\%) had elevated creatinine levels. Of the study participants, 86 (56.58\%) had elevated PSA levels $>10 \mathrm{ng} / \mathrm{mL}$ with a mean level of 18.5 (SD 22.8)ng/mL as summarized in Table 1 .

Table 1: General demographic and clinical characteristics of 152 study participants.

\begin{tabular}{|c|c|c|}
\hline Variable & Frequency & $\begin{array}{l}\text { Mean(SD) or } \\
\text { percent }\end{array}$ \\
\hline Age in years & 152 & $69(9.4)$ \\
\hline \multicolumn{3}{|l|}{ Age group } \\
\hline$<60$ years & 30 & 19.74 \\
\hline $60-70$ years & 55 & 36.18 \\
\hline $70-80$ years & 46 & 30.26 \\
\hline$>80$ years & 21 & 13.82 \\
\hline \multicolumn{3}{|l|}{ Hydronephrosis } \\
\hline YES & 16 & 10.53 \\
\hline $\mathrm{NO}$ & 136 & 89.47 \\
\hline \multicolumn{3}{|l|}{ Creatinine levels } \\
\hline Mean (mmol/dL) & 152 & $91.1(42.9)$ \\
\hline$>120 \mathrm{mmol} / \mathrm{dL}$ & 49 & 32.24 \\
\hline$\leq 120 \mathrm{mmol} / \mathrm{dL}$ & 103 & 67.76 \\
\hline \multicolumn{3}{|l|}{ PSA level } \\
\hline Mean (ng/mL) & 152 & $18.5(22.8)$ \\
\hline$>10 \mathrm{ng} / \mathrm{mL}$ & 86 & 56.58 \\
\hline$<10 \mathrm{ng} / \mathrm{mL}$ & 66 & 43.42 \\
\hline $\begin{array}{l}\text { Mean prostate size } \\
\text { (G) }\end{array}$ & 152 & $92.7(59.7)$ \\
\hline \multicolumn{3}{|l|}{ Histology results } \\
\hline CA prostate & 33 & 21.71 \\
\hline $\mathrm{BPH}$ & 119 & 78.29 \\
\hline \multicolumn{3}{|l|}{ Tumor percent } \\
\hline $\begin{array}{l}>5 \% \text { of tissue } \\
(\mathrm{T} 1 \mathrm{~b})\end{array}$ & 11 & 33.33 \\
\hline $\begin{array}{l}\leq 5 \% \text { of } \\
\text { tissue(T1a) }\end{array}$ & 22 & 66.67 \\
\hline \multicolumn{3}{|l|}{ Gleason score } \\
\hline Grade $1(2-4)$ & 4 & 12.12 \\
\hline Grade $2(5-7)$ & 11 & 33.33 \\
\hline Grade $3(8-10)$ & 18 & 54.55 \\
\hline
\end{tabular}

ФBPH: Benign prostatic hyperplasia; CA: Carcinoma; CI: Confidence interval; CR: Creatinine; G: Grams; IQR: Interquartile range; OR: Odds ratio; PSA: Prostatic specific antigen
Prevalence and associated factors of incidental prostatic carcinoma: In this study, a total of 33 (21.71\%) patients operated for presumed BPH were found to have incidental prostatic carcinoma (Table 1). The T1a tumors were more common at ages $<65$ years $(98.1 \%$ vs. $89.8 \%)$ whereas $\mathrm{T} 1 \mathrm{~b}$ was more common at ages $>65$ years $(10.1 \%$ vs. $1.9 \%$ ) with a Pearson ratio ( $\mathrm{Pr}$ ) of 0.05 (Figure 1). Increased tendency of having poorly differentiated incidental carcinoma was also observed among patients older than 65 years $(13.3 \%$ vs. $9.3 \%, \mathrm{pr}=0.5)$ as summarized in Figure 2. The odds of having incidentally diagnosed prostatic carcinoma were independently associated with age between 70 and 80 years $(\mathrm{AOR}=2.8, \mathrm{p}=0.013)$ and PSA levels of more than $10 \mathrm{ng} / \mathrm{mL}(\mathrm{AOR}=3.2, \mathrm{p}=0.014)$. The difference in distribution of other factors was not statistically significant as summarized in Table 2.

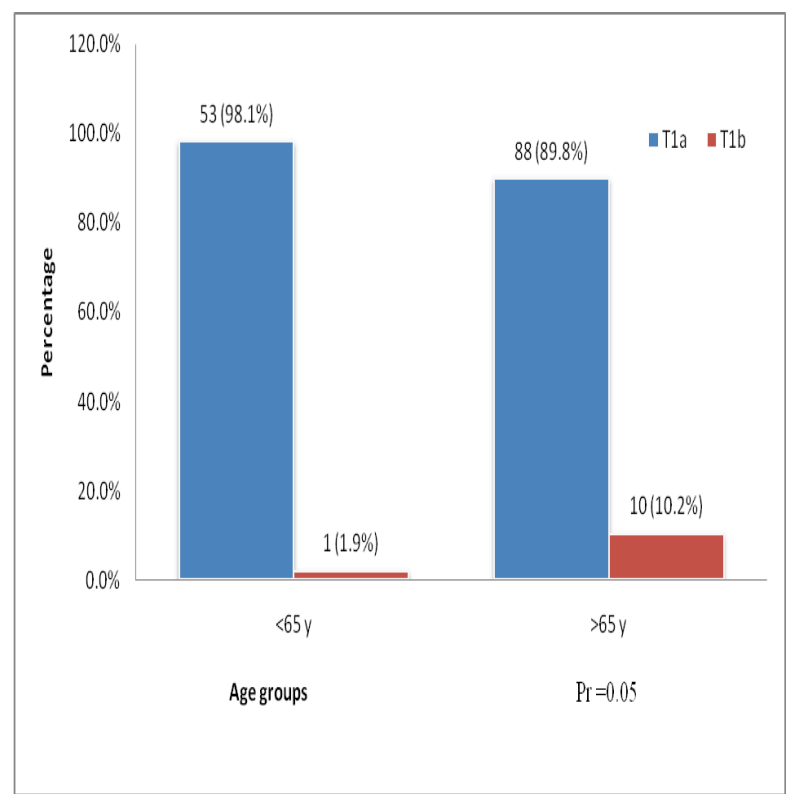

Figure 1: Distribution of TMN by age cutoff of 65 years

DOI: http://dx.doi.org/10.4314/ejhs.v28i1.3 
Table 2: Factors associated with incidentally diagnosed prostatic carcinoma among 152 participants who underwent TURP for presumed BPH.

\begin{tabular}{lcccccc}
\hline Variable & \multicolumn{2}{c}{ Incidental Prostate Carcinoma } & \multicolumn{2}{c}{ Un adjusted } & \multicolumn{2}{c}{ Adjusted } \\
\cline { 2 - 6 } & YES (n=33) & NO (n=119) & OR (95\%CI) & P- Val & OR(94\%CI) & P-Val \\
\hline Mean Age (Y) & $71(8.0)$ & $68(9.6)$ & $1.0(0.9-1.1)$ & 0.071 & $0.9(0.9-1.0)$ & 0.92 \\
Age Group (Y) & & & & & & \\
$\quad \leq 60$ years & $02(06.06)$ & $28(23.53)$ & $0.2(0.0-1.0)$ & 0.040 & & \\
$\quad 60-70$ years & $11(33.33)$ & $44(36.97)$ & $0.9(0.4-1.9)$ & 0.700 & & $\mathbf{0 . 0 1 3}$ \\
$\quad 70-80$ years & $17(51.52)$ & $29(24.37)$ & $3.3(1.5-7.3)$ & 0.003 & $\mathbf{2 . 8}(\mathbf{2 . 5}-\mathbf{6 . 4})$ & \\
$\quad>80$ years & $03(09.09)$ & $18(15.13)$ & $0.6(0.2-2.0)$ & 0.379 & & \\
Hydronephrosis & & & & & & \\
$\quad$ YES & $04(12.12)$ & $012(10.08)$ & & & & \\
$\quad$ NO & $29(87.88)$ & $107(89.92)$ & $1.2(0.4-4.0)$ & 0.736 & & \\
CR levels & & & & & & \\
Mean (mmol/dL) & $103(79.4)$ & $87.8(25.2)$ & $1.0(0.9-1.0)$ & 0.127 & $1.0(0.9-1.1)$ & \\
$\quad>120 \mathrm{mmol} / \mathrm{dL}$ & $13(39.39)$ & $36(30.25)$ & & & & \\
$\quad \leq 120 \mathrm{mmol} / \mathrm{dL}$ & $20(60.61)$ & $83(69.75)$ & $1.5(0.7-3.3)$ & 0.322 & & \\
PSA Levels & & & & & & \\
Mean (ng/mL) & $34.1(26.7)$ & $13.4(18.8)$ & $1.1(1.0-1.2)$ & $<0.001$ & $1.0(1.0-1.1)$ & 0.33 \\
$\quad>10 \mathrm{ng} / \mathrm{mL}$ & $26(78.79)$ & $60(50.42)$ & & & & $\mathbf{0 . 0 1 4}$ \\
$\quad \leq 10 \mathrm{ng} / \mathrm{mL}$ & $07(21.21)$ & $59(49.58)$ & $3.7(1.5-9.0)$ & 0.005 & $\mathbf{3 . 2}(\mathbf{1 . 3 - 8 . 1 )}$ & \\
Prostate size (G) & $83.4(51.1)$ & $95.2(61.9)$ & $1.0(0.9-1.0)$ & 0.369 & & \\
Biopsy Size (G) & $15.4(18.8)$ & $20.2(26.2)$ & $1.0(0.9-1.1)$ & 0.352 & & \\
\hline
\end{tabular}

qBPH: Benign Prostatic Hyperplasia; CI: Confidence interval; CR: Creatinine; G: grams; OR: Odds ratio; PSA: Prostatic specific antigen; P-Val: P-value; TURP: Trans urethral resection Prostatectomy

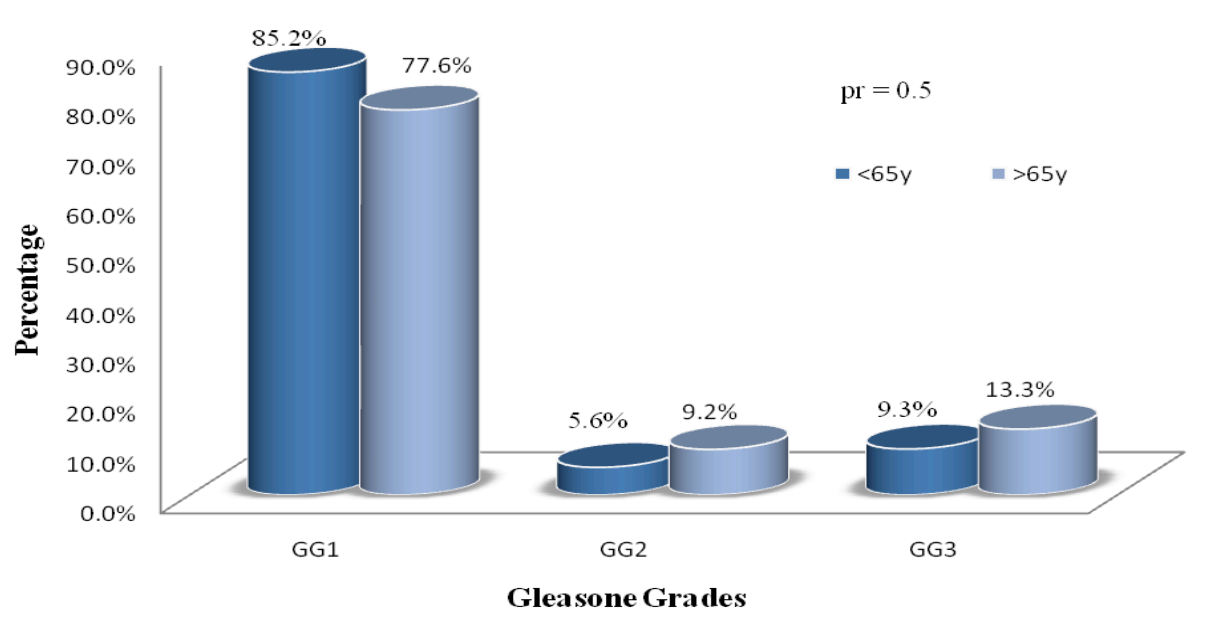

GG1: Gleason grade 1; GG2: Gleason grade 2; GG3: Gleason grade 3

Figure 2: Distribution of Gleason grades by age cutoff of 65 years

DOI: http://dx.doi.org/10.4314/ejhs.v28i1.3 


\section{DISCUSSION}

The objective of this study was to determine the prevalence and assess the associated factors of incidental prostatic carcinoma among patients operated for presumed BPH. Several studies have had comparable findings. The prevalence from this study is relatively similar with a prevalence rate of $25 \%$ reported earlier in 1992 by Bostwick and colleagues among patients who underwent TURP (7). However, compared to our finding, a much lower prevalence of $1.4 \%$ of incidental prostatic carcinoma was reported recently by Otto and colleagues from the United States of America (14). Other lower prevalence rates include those reported from Brazil in 2006 where $6.2 \%$ of patients who underwent TURP had incidental prostatic carcinoma (17), and UK in 2009 where $11.4 \%$ prevalence rate of incidentally diagnosed prostatic carcinoma was reported among patients operated for presumed BPH (16). Compared to our finding, a higher prevalence of $40 \%$ was reported previously in 1996 among patients operated for bladder cancer (8). The differences in prevalence of incidental prostatic carcinoma in these studies can largely be attributed to the differences in diagnostics advances, noting here that most findings from studies that were prior use of PSA report much higher prevalence of incidentally diagnosed prostatic carcinoma. In support of this observation, Jones and colleagues in their study also found that more prostatic carcinomas were incidentally diagnosed before the advent of PSA (14.9\% vs. $5.2 \%)(18)$.

A number of factors were assessed for potential association with incidentally diagnosed prostatic carcinoma. It was found in the current study that advanced age and elevated PSA levels had a significant association with incidentally diagnosed prostatic carcinoma. These findings are consistent with those reported by Bright and colleague in 2009 form UK where advanced age (mean age 76 vs. 71) and raised PSA levels were also found to be predictive of Incidentally diagnosed prostatic carcinoma (16). It was also reported in Brazil that advanced mean age (73.9 vs. 68.0, $\mathrm{p}=0.003)$ and suspicious rectal examination $(23.0 \%$ vs. $3.4 \%, \mathrm{p}=0.016)$ were significantly associated with incidental finding of Prostatic carcinoma. However, in this study, the PSA levels did not have any significant association with incidental prostatic carcinoma as found in other studies, and the authors thought that this could be explained by a longer time of indwelling bladder catheter before surgery which could also cause high levels PSA (17).

These results are clinically important especially in resource limited setting like ours suggesting that as many as $21.6 \%$ of the malignant prostatic tumors are potentially missed among patients presenting with obstructive prostate presumed to be $\mathrm{BPH}$. This rate is significantly higher as compared to those from resource rich countries $(14,17)$, and strategies should be devised to increase the detection rate of this disease at its earliest and potentially manageable stage. In resource limited settings like Tanzania where PSA is not readily available, a targeted PSA screening could be useful in early identification of patients who can benefit from biopsy and early treatment. Prior studies have indicated that PSA done in patients with suspicious per rectal examination at a risk age still significantly increases the detection rate before surgery thus reducing the rate of incidentally diagnosed prostatic carcinoma (17-19). While in the index study the age group of 70-80 years was the most associated factor with incidental prostatic carcinoma, previous studies had indicated that any age above 65 years is at highest risk of the most advanced local prostatic lesions with poor outcome. For instance, in 2016, Perera and colleagues showed that T1b's were more common among ages above 65 years with highest Gleason score of more than 7 (15). Our study had similar observation that patients who were older than 65 years were as well more likely to have

DOI: http://dx.doi.org/10.4314/ejhs.v28i1.3 
T1b tumors as compared to those younger than 65years with an increased tendency to have poorly differentiated prostatic carcinoma than their younger counter parts. Ahmad and colleagues from Ireland in 2012 in addition found that the survival rate was significantly reduced among those patients with these advanced lesions (20). In this study, it was shown that with an overall survival of $88 \%$ at 10 years of watchful waiting, the survival rate was only $50 \%$ among those patients with $\mathrm{T} 1 \mathrm{~b}$ incidental prostatic carcinoma with increased cancer specific mortality of $20 \%$.

Most prostatic carcinoma diagnosed among younger patients have also been shown to be of less advanced malignant lesions of T1a (15). This is similar with our finding where we also observed that younger patients had more of the T1a lesions compared to those older than 65 years. Patients diagnosed with these earlier lesions have been shown to have a much better outcome on treatment, with radical prostatectomy being the preferred modality to TUPR $(21,22)$. In 2011, Bill-Axelson and colleagues could show that patients who underwent radical prostatectomy following early diagnosis of their prostatic cancer had a significant reduction of mortality (23). In 2014, Bill-Axelson et al. additionally found that patients who were diagnosed and underwent prostatectomy at ages younger than 65 years had a reduced mortality rate by more than $25 \%$ after 23 years of follow-up (24). In our setting, we could also reduce the rate of incidentally diagnosed carcinoma of prostate by devising strategies that address a focused PSA screening of patients older than 60 years with suspicious DRE and subject them to biopsy for confirmatory histology examination. This study had a number of limitations. Being a single center study, the results from this study may not be generalizable. Also, being a retrospective study, missing data was a common problem. Additionally, the outcome of these patients could not be determined. However, this is one of the fewer studies that have assessed the prevalence of incidentally diagnosed prostatic carcinoma in Tanzania.

In conclusion, this study has shown that incidental prostatic carcinoma is very prevalent among patients operated for presumed benign prostate enlargement. The risk of incidentally diagnosed prostatic carcinoma is highest at an age group of 70-80 years and those with elevated PSA levels above $10 \mathrm{ng} / \mathrm{mL}$. Strategies to reduce this magnitude are required. A national awareness campaign coupled with focused PSA screening of patients above 60 years could potentially increase the detection rate of prostatic carcinoma and therefore reduce the magnitude of the incidental diagnosis of this disease.

\section{ACKNOWLEDGMENT}

The authors would like to acknowledge the support given by the staff members at pathology and Record departments during the study period.

\section{REFFERENCES}

1. Bouchelouche K, Turkbey B, Choyke PL. Advances in imaging modalities in prostate cancer. Curr Opin Oncol. 2015 May;27(3):224-31.

2. Jemal A, Siegel R, Ward E, Murray T, Xu J, Smigal C, et al. Cancer statistics, 2006. $C A$ Cancer J Clin. 2006 Mar-Apr;56(2):106-30.

3. Haas GP, Delongchamps N, Brawley OW, Wang CY, de la Roza G. The worldwide epidemiology of prostate cancer: perspectives from autopsy studies. Can J Urol. 2008 Feb;15(1):3866-71.

4. Zlotta AR, Egawa S, Pushkar D, Govorov A, Kimura T, Kido M, et al. Prevalence of prostate cancer on autopsy: cross-sectional study on unscreened Caucasian and Asian men. J Natl Cancer Inst. 2013 Jul 17;105(14):10508.

5. Stamatiou K, Alevizos A, Agapitos E, Sofras F. Incidence of impalpable carcinoma of the prostate and of non-malignant and precarcinomatous lesions in Greek male population: an autopsy study. Prostate. 2006 Sep 1;66(12):1319-28.

6. Haas GP, Delongchamps NB, Jones RF, Chandan V, Serio AM, Vickers AJ, et al. Needle biopsies on autopsy prostates: sensitivity of cancer detection based on true prevalence. J Natl Cancer Inst. 2007 Oct 3;99(19):1484-9.

DOI: http://dx.doi.org/10.4314/ejhs.v28i1.3 
7. Bostwick DG, Cooner WH, Denis L, Jones GW, Scardino PT, Murphy GP. The association of benign prostatic hyperplasia and cancer of the prostate. Cancer. $1992 \mathrm{Jul}$ 01;70(1 Suppl):291-301.

8. Abbas F, Hochberg D, Civantos F, Soloway M. Incidental prostatic adenocarcinoma in patients undergoing radical cystoprostatectomy for bladder cancer. Eur Urol. 1996;30(3):322-6.

9. Troncoso P, Babaian RJ, Ro JY, Grignon DJ, von Eschenbach AC, Ayala AG. Prostatic intraepithelial neoplasia and invasive prostatic adenocarcinoma in cystoprostatectomy specimens. Urology. 1989 Dec;34(6 Suppl):52.

10. Hamilton W, Sharp DJ, Peters TJ, Round AP. Clinical features of prostate cancer before diagnosis: a population-based, case-control study. Br J Gen Pract. 2006 Oct;56(531):756.

11. Ellis WJ, Chetner M, Preston S, Brawer M. Diagnosis of prostatic carcinoma: the yield of serum prostate specific antigen, digital rectal examination and transrectal ultrasonography. The Journal of urology. 1994;152(5 Pt 1):1520-5.

12. Catalona W, Richie J, Ahmann FR, Hudson M, Scardino P, Flanigan R, et al. Comparison of digital rectal examination and serum prostate specific antigen in the early detection of prostate cancer: results of a multicenter clinical trial of 6,630 men. The Journal of urology. 1994;151(5):1283-90.

13. Chan TY, Partin AW, Walsh PC, Epstein JI. Prognostic significance of Gleason score $3+4$ versus Gleason score $4+3$ tumor at radical prostatectomy. Urology. 2000;56(5):823-7.

14. Otto B, Barbieri C, Lee R, Te AE, Kaplan SA, Robinson $\mathrm{B}$, et al. Incidental prostate cancer in transurethral resection of the prostate specimens in the modern era. Adv Urol. 2014;2014:627290.

15. Perera M, Lawrentschuk N, Perera N, Bolton $\mathrm{D}$, Clouston D. Incidental prostate cancer in transurethral resection of prostate specimens in men aged up to 65 years. Prostate Int. 2016 Mar;4(1):11-4.
16. Bright EA, Manuel C, Goddard JC, Khan MA. Incidence and factors predicting the detection of prostate cancer after transurethral resection of the prostate for clinically benign disease. Urol Int. 2009;83(2):171-4.

17. Antunes AA, Freire Gde C, Aiello Filho D, Cury J, Srougi M. Analysis of the risk factors for incidental carcinoma of the prostate in patients with benign prostatic hyperplasia. Clinics (Sao Paulo). 2006 Dec;61(6):545-50.

18. Jones JS, Follis HW, Johnson JR. Probability of finding T1a and T1b (incidental) prostate cancer during TURP has decreased in the PSA era. Prostate Cancer Prostatic Dis. 2009;12(1):57-60.

19. Di Silverio F, Gentile V, De Matteis A, Mariotti G, Giuseppe V, Luigi PA, et al. Distribution of inflammation, pre-malignant lesions, incidental carcinoma in histologically confirmed benign prostatic hyperplasia: a retrospective analysis. Eur Urol. 2003 Feb;43(2):164-75.

20. Ahmad S, O'Kelly F, Manecksha RP, Cullen IM, Flynn RJ, McDermott TE, et al. Survival after incidental prostate cancer diagnosis at transurethral resection of prostate: 10-year outcomes. Ir J Med Sci. 2012 Mar;181(1):27.

21. Augustin H, Erbersdobler A, Hammerer PG, Graefen M, Huland H. Prostate cancers in the transition zone: Part 2; clinical aspects. BJU Int. 2004 Dec;94(9):1226-9.

22. Erbersdobler A, Augustin H, Schlomm T, Henke RP. Prostate cancers in the transition zone: Part 1; pathological aspects. BJU Int. 2004 Dec;94(9):1221-5.

23. Bill-Axelson A, Holmberg L, Ruutu M, Garmo $\mathrm{H}$, Stark JR, Busch C, et al. Radical prostatectomy versus watchful waiting in early prostate cancer. $N$ Engl J Med. 2011 May 05;364(18):1708-17.

24. Bill-Axelson A, Holmberg L, Garmo H, Rider JR, Taari K, Busch C, et al. Radical prostatectomy or watchful waiting in early prostate cancer. $N$ Engl J Med. 2014 Mar 06;370(10):932-42. 